\title{
The CERN Bomb
}

\section{ISSN : 2688-836X}

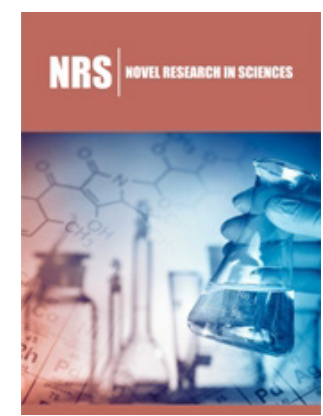

*Corresponding author: Otto E Rossler, Faculty of Science, university of Tübingen, Auf der Morgenstelle 8, 72076 Tübingen, Germany

Submission: 侮July 15, 2019

Published: 漈August 01, 2019

Volume 1 - Issue 4

How to cite this article: Otto E Rossler. The CERN Bomb. Nov Res Sci.1(4). NRS.000516.2019.

DOI: 10.31031/NRS.2019.1.000516

Copyright@ Hasan Khan MM, This article is distributed under the terms of the Creative Commons Attribution 4.0 International License, which permits unrestricted use and redistribution provided that the original author and source are credited.

\section{Otto E Rossler*}

Faculty of Science, University of Tübingen, Germany

\section{Opinion}

CERN dares non-renew its latest scientific safety report LSAG for 11 years. But it the same time hides this fact from the public eye by keeping the report undated so as to be able to continue. Now this could be a minor coup since scientific results impacting on global survival on an ultra-short basis are rare and far between. So, I have to explain to you why there is indeed an occasion for concern here for once. 90 years ago, Fritz Zwicky from Switzerland proposed in Pasadena that light racing through the cosmos loses energy to the moving galaxies which it is grazing. No one believed him. But ten years ago, a new fundamental science, Cryodynamics, sister of Thermodynamics, was found which directly confirms him. This science is very promising because it for the first time provides a mechanism by which fusion reactors can be interactively controlled and hence become a realistic economic option. Billions of dollars are affected (compare my 2011 YouTube talk "Billion Dollar Zwicky"). But: Cryodynamics also proves that CERN is geocidal at large odds.

Unfortunately, though, CERN also is a billion dollars business. So, CERN resolved to sit it out. Indeed, all media across the earth decided to ignore the option of checking on an earlier version of the Internet to verify that CERN indeed can't renew its planetary safety report LSAG from early 2008. After all, CERN is a most honorable organization. So, it could happen that the CERN danger would get suppressed by the media - an event which in view of its similarity to Watergate can be called CERNgate. Cerngate sounds more harmless than Cernbomb. But for once it is the same thing. Never before in history did there exist a larger planet-threatening bomb. But: Hush little babe don't you cry, your dad is going to let you die.

Thus, if you so wish, there never was a more tear-jerking development in terrestrial history before. But alors, the nerves of all parents have no problem living with it. And of course, it is not all parents that abide, it is only the small fraction of media persons who (a) have learned of the CERN fraud and (b) happen to have a young family of their own. So, the planet-wide silence of the lambs is absolutely understandable as a fact. Instead of "all they are crying" we have "all they are ready (to die)". 